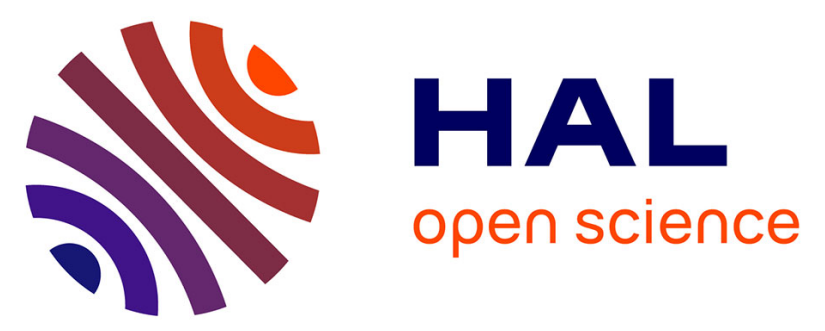

\title{
Polo-like kinase 2 () is a novel epigenetically regulated gene in acute myeloid leukemia and myelodysplastic syndromes: genetic and epigenetic interactions
}

Leonidas Benetatos, Aggeliki Dasoula, Eleftheria Hatzimichael, Nelofer Syed, Maria Voukelatou, George Dranitsaris, Konstantinos L. Bourantas, Tim Crook

\section{- To cite this version:}

Leonidas Benetatos, Aggeliki Dasoula, Eleftheria Hatzimichael, Nelofer Syed, Maria Voukelatou, et al.. Polo-like kinase 2() is a novel epigenetically regulated gene in acute myeloid leukemia and myelodysplastic syndromes: genetic and epigenetic interactions. Annals of Hematology, 2011, 90 (9), pp.1037-1045. 10.1007/s00277-011-1193-4 . hal-00616294

\section{HAL Id: hal-00616294 https://hal.science/hal-00616294}

Submitted on 22 Aug 2011

HAL is a multi-disciplinary open access archive for the deposit and dissemination of scientific research documents, whether they are published or not. The documents may come from teaching and research institutions in France or abroad, or from public or private research centers.
L'archive ouverte pluridisciplinaire HAL, est destinée au dépôt et à la diffusion de documents scientifiques de niveau recherche, publiés ou non, émanant des établissements d'enseignement et de recherche français ou étrangers, des laboratoires publics ou privés. 
Polo-like kinase 2 (SNK/PLK2) is a novel epigenetically regulated gene in acute myeloid leukemia and myelodysplastic syndromes: genetic and epigenetic

\section{interactions}

Leonidas Benetatos ${ }^{1}$, Aggeliki Dasoula ${ }^{1}$, Eleftheria Hatzimichael ${ }^{1}$, Nelofer Syed ${ }^{2}$, Maria Voukelatou ${ }^{1}$, George Dranitsaris ${ }^{3}$, Konstantinos L. Bourantas ${ }^{1}$, Tim Crook $^{2}$

${ }^{1}$ Department of Hematology, University Hospital of Ioannina, Greece

${ }^{2}$ Imperial College, Charing Cross Hospital, London, United Kingdom

${ }^{3}$ Department of Medical Oncology, Princess Margaret Ho spital, Toronto, Canada

Short title: SNK/PLK2 methylation in AML and MDS

\section{Corresponding author}

Leonidas Benetatos

Department of Hemato logy, University Hospital of Ioannina

Niarchos Avenue, 45500

Ioannina

\section{GREECE}

Tel: +302651099729

Fax: +302651046617

e-mail: benetatosleon@yahoo.com

me01532@cc.uoi.gr 


\begin{abstract}
Polo- like kinase 2 (SNK/PLK2), a transcriptional target for wild-type p53 and is hypermethylated in a high percentage of multiple myeloma and B-cell lymphomas patients. Given these data, we sought to study the methylation status of the specific gene in AML and MDS, and to correlate it with clinical and genetic features. Using methylation specific PCR (MSP), we analyzed the methylation profile of 45 cases of acute myeloid leukemia (AML) and 43 cases of myelodysplastic syndrome (MDS). We also studied the distribution of MTHFR A1298C and MTHFR C677T polymorphisms and FLT3 mutations in AML patients, and correlated the results with hypermethylation in the SNK/PLK2 CpG island. The SNK/PLK2 CpG island was hypermethylated in $68.9 \%$ and $78.4 \%$ of AML and MDS cases respectively. Cases with hypermethylation had a trend towards more favourable overall survival (OS). There was no association between different MTHFR genotypes and susceptibility to develop AML. SNK/PLK2 hypermethylation combined with the MTHFR AA1298 genotype was associated with a tendency for a better OS. Similarly, patients with SNK/PLK2 hypermethylation combined with the MTHFR CT677 polymorphism had a better OS $(\mathrm{HR}=0.34, \mathrm{p}=0.017)$. SNK/PLK2 methylation associated with unmutated FLT3 cases had a trend for better OS compared to patients with mutated FLT3 gene. SNK/PLK2 is a novel epigenetically regulated gene in AML and MDS and methylation occurs at high frequency in both diseases. As such SNK/PLK2 could represent a potential pathogenetic factor, although additional studies are necessary to verify its exact role in disease pathogenesis.
\end{abstract}

Key words: $S N K / P L K 2$, methylation, AML, MDS, MTHFR polymorphisms 


\section{Introduction}

DNA cytosine methylation is the best characterized epigenetic marker, and is involved in the control of gene expression and the nuclear architecture of the cell [1]. Dynamic changes in promoter methylation are important for the timely and appropriate expression of growth factors and their cognate receptors, cytokines and other molecules necessary for normal myeloid development [2]. Aberrant hypermethylation in the $\mathrm{CpG}$ islands frequently results in the transcriptional silencing of tumour suppressor genes and is an important event in carcinogenesis $[1,3]$. Genes from multiple functional classes are subject to silencing in human cancer, including those involved in DNA repair, apoptosis, angiogenesis, cell cycle regulation, cell-tocell interaction, and in metabolism of carcinogens. $\mathrm{CpG}$ methylation is established and maintained by the DNA methyltransferases [4], and aberrant expression or recruitment of the DNA methyltransferases may result in hypermethylation of specific target genes, thus contributing to oncogenesis-leukemogenesis [5]. In hematopoietic neoplasia, DNA hypermethylation is a common gene inactivating mechanism and disease-specific methylation patterns for individual genes have been described [6]. In acute myeloid leukemia (AML), aberrant hypermethylation is common, with $70 \%$ of AML cases having at least one methylated gene at diagnosis, and hypermethylated genes have clinical implications. Methylation of genes involved in cell cycle control and apoptosis may also play a role in the pathogenesis of myelodysplastic syndromes (MDS) [6].

The Polo-like kinases $(P L K)$ are a highly conserved family of proteins implicated in regulation of the G2-M transition and mitotic entry during the cell cycle. PLK also play a role in bipolar spindle formation during mitosis, centrosome maturation and 
separation, and M-phase exit through destruction of cyclin B and inactivation of $p 34^{c d c 2}[7]$.

Polo- like kinase $2(S N K / P L K 2)$ is expressed in a tissue specific manner in neurons, heart and lung [8]. The protein has a role in regulating cell proliferation in G1 phase [9], is required for centriole duplication and centrosome function during $\mathrm{S}$ phase $[9,10]$ and is also a cellular stress responsive gene [11]. SNK/PLK2 may have a role in embryogenesis as $S N K / P L K 2^{-/-}$mouse embryos show a delay in skeletal development and retarded growth [12]. SNK/PLK2 is transcriptionally induced by $p 53$ and its silencing in the presence of cytotoxic drugs such as taxol results in increased apoptosis [13]. SNK/PLK2 protein may possess oncogenic activity [8] as its deregulation results in multinucleated phenotypes, one of the hallmarks in carcinogenesis [14]. It is known that centrosome abnormalities are present early in the development of aplastic anemia, AML and MDS, including numerical and structural centrosome aberrations which positively correlate with numerical chromosome changes [15]. SNK/PLK2 also has tumour suppressor functions which are regulated by the tumor microenvironment and may inhibit mTOR pathway through interaction with the TSC1 and TSC2 complexes [8,16]. SNK/PLK2 has been found to be hypermethylated and consequently silenced in a high percentage of multiple myeloma [17] and B-cell lymphomas patients but not in breast, and in head and neck carcinomas [18], suggesting a physiological function in regulation of B-cell proliferation and differentiation. As these results imply that SNK/PLK2 hypermethylation is hematopoietic tissue-specific, we sought to study the methylation status of the specific gene in AML and MDS, and to correlate it with clinical and genetic features. 


\section{Materials and methods}

\section{Patients}

Eighty-eight patients with myeloid malignancies who presented at the Department of Haematology of the University Hospital of Ioannina were included in the study. Bone marrow and peripheral blood genomic DNA from 45 AML patients (51.1\%) and 43 MDS patients $(48.9 \%)$ was obtained at diagnosis. None of the patients had received any prior treatment. There were 30 female patients (34.1\%) and 58 male patients $(65.9 \%)$, with mean age $71.5 \pm 13.7$ years (range 16-92 years). All patients were classified according to the revised 2008 WHO classification [19] and MDS diagnosis was based on the recently published diagnostic criteria [20]. The WHO classificationbased prognostic scoring system for MDS (WPSS) [21] was used for risk stratification of MDS patients. Conventional cytogenetic analysis was performed in all but 12 AML patients and all patients were subdivided into good, intermediate and poor karyotypes as described in the WPSS definition for MDS, and the SWOG/ECOG cytogenetic classification system for AML patients [22]. MDS patients with no available cytogenetic analysis and patients who were lost to follow-up were excluded from the study. All patients were further evaluated, for statistical purposes, according to their haematological parameters as having anaemia (haemoglobin $<100 \mathrm{~g} / \mathrm{l}$ ), leukocytosis or leukopenia (white blood cell count $<1.5 \times 10^{9} / 1$ or $>30 \times 10^{9} / 1$ ), and thrombocytopenia (platelet count $\left.<100 \times 10^{9} / \mathrm{I}\right)$. Treatment in AML patients consisted of Ara-C and id arubicin, followed by consolidation with intermed iate/high dose Ara-C, idarubicin \pm etoposide or azacytidine for patients not suitable for intensive chemotherapy. Treatment in MDS patients consisted of red blood cell and/or platelet transfusions as required, recombinant human erythropoietin, granulocyte-colony stimulating factor administration, and azacytidine. Patient characteristics are shown in Table 1. 
Bone marrow samples obtained from 15 patients who underwent diagnostic procedures for borderline cytopenias, and were proved to have no hematological malignancies or solid tumor infiltration were controls.

Informed consent was obtained from all patients and control subjects, and the study was approved by the Scientific Committee of the University Hospital of Ioannina.

\section{SNK/PLK2 methylation analysis}

DNA extraction from bone marrow nucleated cells and bisulphite treatment were performed using the QIAmp DNA blood mini Kit (Qiagen), and the EZ-DNA methylation kit (Zymo Research Inc.) respectively, according to the manufacturers' protocols. The methylation status of the $S N K / P L K 2 \mathrm{CpG}$ island was determined by using methylation-specific PCR (MSP) using the HotStarTaqMaster Mix kit (Qiagen). All PCR reactions were run in duplicates with positive controls DNA (CpG Genome $^{\mathrm{TM}}$ Universal Methylated, Chemicon International), and blanks (samples containing no DNA).

\section{Methylenetetrahydrofolatereductase (MTHFR) A1298C and C677Tgenotyping}

Genotyping for both MTHFR polymorphisms used genomic DNA extracted from peripheral blood with the QIAamp DNA mini blood kit (Qiagen), as described previously [23]. For PCR, the HotStarTaq Master Mix kit was used according to the manufacturer's instructions (Qiagen). PCR reactions were carried out using the HotStarTaq DNA polymerase (Qiagen). Amplified MTHFR A1298C PCR products (163bp) were digested with MboII (New England BioLabs), resolved on 4\% agarose gels and visualised after ethidium bromide staining. Wild type (1298AA) produced 
fragments of 56, 31, 30, 28 and 18bp, heterozygotes (1298AC) produced fragments of 84, 56, 31,30, 28 and 18bp and homozygotes (1298CC) produced fragments of 84, 31,30, and 18bp. MTHFR C677T-amplified PCR products (198bp) were digested with the HinfI enzyme (New England BioLabs), producing a single band at 198bp for wild type 677CC, fragments of 198, 175, and 23bp for 677CT heterozygotes, and fragments of 175 and 23bp for homozygous $677 \mathrm{TT}$.

\section{FLT3 mutation analysis}

Genomic DNA was isolated from bone marrow samples using the QIAamp DNA mini blood kit (Qiagen) according to the manufacturer's instructions. Mutational analysis of internal tandem duplication (ITD) of the FLT3 gene was restricted to exons 11 and 12 . Primers used in the experimental procedures are shown in Table 2.

\section{Statistical analysis}

Demographic and clinical data were analyzed descriptively as means, medians, or proportions. Survival curves were generated using the method of Kaplan-Meier and compared with the log-rank test. Patients alive or lost to follow up as of after March 1, 2010 were censored. In an exploratory analysis the relative risk of death between various subgroups such as SNK/PLK2 was estimated using Cox Proportional Hazard regression with only a single predictor variable remaining in the final model. All of the statistical analyses were performed using Stata, release 9.0 (Sata Corp., College Station, Texas, USA). 


\section{Results}

\section{SNK/PLK2 is methylated in MDS}

Using MSP, we analyzed methylation in the CpG island of SNK/PLK2 in a series of 88 bone marrow samples from patients with myeloid malignancies. Methylation in SNK/PLK2 was observed in 69/88 cases $(78.4 \%)$ and in none of the control samples that were examined $(\mathrm{p}=0.0004)$ (Figure 1). Methylation was detected in 38 of 43 (88.4\%) MDS patients, including 6 patients (14\%) with refractory anemia, 2 patients (4.7\%) with refractory neutropenia, 1 patient $(2.3 \%)$ with refractory thrombocytopenia, 16 patients $(37.2 \%)$ with refractory cytopenias with multi-lineage dysplasia, 5 patients (11.6\%) with refractory anemia with excess of blasts-I, and 6 patients (14\%) with refractory anemia with excess of blasts-II. Twenty-nine (76.3\%) presented good prognosis karyotype, 3 (7.9\%) had intermediate risk karyotype, and 6 (15.8\%) had poor prognosis karyotype. With regard to the WPSS prognostic system 6 patients $(15.8 \%)$ belonged to the very low risk group of patients, 12 patients $(31.6 \%)$ belonged to the low risk group. SNK/PLK2 methylation was detected in 8 (21.1\%), 9 $(23.7 \%)$, and $3(8 \%)$ patients of the intermediate risk, high risk, and very high risk group respectively. No significant association was observed between blood cell counts, WHO subtype, WPSS score, cytogenetic features and methylation. MDS patients' data presenting SNK/PLK2 methylation are shown on Table 3. Median overall survival (OS) for the entire group of patients was 8 months and 21 months for the MDS patients. Patients with methylated SNK/PLK2 had a median OS of 10 months while individuals lacking methylation had a median OS of 6 months, a difference that was not significant $(\mathrm{HR}=0.86, \mathrm{p}=0.62)$. MDS patients had a median OS of 21 months and of 19.5 months, for those patients with abnormally methylated 
and unmethylated gene respectively. However, the difference in OS was not significant $(\mathrm{HR}=1.35, \mathrm{p}=0.62)$.

\section{SNK/PLK2 is methylated in AML}

SNK/PLK2 methylation was detected in 31 of $45(68.9 \%)$ AML patients, of which 2 (6.5\%), $15(48.4 \%)$, and $4(12.9 \%)$ patients presented good, intermediate, and bad prognosis karyotype respectively. According to the WHO classification 1 patient (2.2\%) was characterized by the $t(8 ; 21)$ genetic abnormality, 1 patient $(2.2 \%)$ had the $\mathrm{t}(15 ; 17)$ characteristic abnormality, 10 patients $(23.3 \%)$ had AML with myelodysplasia-related changes, 1 patient (2.2\%) had therapy related AML, 4 patients (8.9\%) had AML with minimal differentiation, 6 patients $(13 \%)$ had AML without maturation, 3 patients $(6.7 \%)$ had AML with maturation, 3 patients $(6.7 \%)$ had acute myelomonocytic leukemia, and finally 2 patients (4.4\%) had acute monoblastic/monocytic leukemia. Patients' data are shown on Table 4. As with the MDS patients, no significant association between SNK/PLK2 methylation, karyotype, and clinical parameters was observed. Median OS was 3.5 months for all AML patients, 3 and 5 months for those with unmethylated and methylated SNK/PLK2 respectively. Kaplan-Meier curves for AML and MDS are shown in table 5. The difference among the two groups was not significant $(\mathrm{HR}=1.03, \mathrm{p}=0.9)$.

\section{MTHFR A1298C and C677T in AML}

The distribution of MTHFR A1298C and C677T polymorphisms was determined in all AML patients. First, for the MTHFR 1298AA, 1298AC, and 1298CC 
polymorphisms we observed $27(60 \%), 14$ (31.1\%), and 4 (8.9\%) AML cases respectively. Of the cases with $S N K / P L K 2$ methylation, 19 patients, $(63.1 \%)$ were of AA genotype, while 9 patients (29\%) had the AC polymorphism and 3 patients (9.7\%) had the CC polymorphism. There was no significant association between distribution of polymorphisms and blood cell counts, WHO subtypes and karyotype. Median OS was 3 months, 7 months, and 2 months for the AA, AC, and the CC polymorphisms respectively. Cox regression analysis relative to the AA polymorphism demonstrated that the difference in OS between patients with the various $\mathrm{A} 1298 \mathrm{C}$ genotypes was not significant $(\mathrm{HR}=1.44, \mathrm{p}=0.32)$ (Table 6a). Comparison among patients with SNK/PLK2 methylation and the A1298C polymorphisms demonstrated that those patients who had both hypermethylated SNK/PLK2 and the AA genotype had a tendency for a better OS $(\mathrm{HR}=1.80, \mathrm{p}=0.37)$ in comparison with those individuals with the AC and CC genotypes (Table 6b).

The distribution, of the C677T polymorphisms was as follows: 9 patients (20\%) presented the CC genotype, 31 patients $(68.9 \%)$ had the CT genotype, and 5 patients (11.1\%) had the TT genotype. SNK/PLK2 methylation was observed in 7 patients (22.6\%), in 22 patients (71\%), and in 2 patients $(6.4 \%)$ with the CC, CT, and TT genotypes respectively. Again, no significant association between distribution of polymorphisms and blood cell counts, WHO subtypes and karyotype was observed. Median OS was 2 months for the CC genotype, 7 months for the CT genotype, and 6 months for those patients with the TT genotype. Survival analysis relative to the CC genotype shown that AML patients with the CT polymorphism had a better OS $(\mathrm{HR}=0.34, \mathrm{p}=0.017)($ Table $6 \mathrm{c})$. In respect to the methylation status of the SNK/PLK2 and C677T subtypes, patients with both SNK/PLK2 methylation and the CT genotype had a better OS $(\mathrm{HR}=0.3, \mathrm{p}=0.05)$ (Table $6 \mathrm{~d})$. 


\section{FLT3 mutation analysis in AML}

FLT3-ITD was detected in only 7 (15.6\%) AML patients and there were no significant findings in comparison to their various clinical features. SNK/PLK2 methylation was detected in $4(57.1 \%)$ out of the 7 patients. Median OS was 2 months and 6 months for patients who were positive and negative for FLT3-ITD respectively. Individuals with the FLT3-ITD had a shorter OS although not significant ( $\mathrm{p}=0.08$ by the long rank test). Those patients with both methylated SNK/PLK2 and unmutated FLT3 gene had a trend for better OS $(\mathrm{HR}=0.38, \mathrm{p}=0.1)$ in comparison to the patients harbouring FLT3 mutations and SNK/PLK2/ methylation. No impact on OS between association of the FLT3-ITD, MTHFR C677T and MTHFR A1298C was observed. 


\section{Discussion}

Acute myeloid leukemia is a heterogeneous group of clonal hematopoietic progenitor cell disorders with a diverse range of morphologic, cytogenetic, immunophenotypic and molecular features [24]. The MDS are characterized by stem cell clonal myelopoiesis, commonly a hypercellular-dysplastic bone marrow, peripheral blood cytopenias and a tendency to progression to AML $[25,26]$. The molecular pathogenesis of both disorders is characterized by genetic changes commonly targeting genes encoding proteins functioning in cell proliferation and myeloid differentiation [22,27]. In addition to the genetic changes, DNA methylation and associated gene silencing play an important role in the pathogenesis of AML and MDS [28]. Elegant work by Figueroa et al [29] showed that CpG methylation is not randomly distributed in leukemic blasts and so AML can be categorized and grouped according to the methylation profile. In the same study, it was also shown that oncoproteins can drive methylation resulting in leukemogenesis and that clinical outcome can be predicted independent of cytogenetic class. A common epigenetic signature implicated in leukemogenesis was also described [29]. Moreover, aberrant promoter methylation, in terms of frequency and density, correlate with clinical outcome and is also increased at disease relapse [30,31]. As in AML, DNA methylation occurs in MDS, is associated with biological and clinical features of the disease, and appears to be a progressive process already present in low-risk MDS that significantly increases as the disease evolves [32-34]. A prognostic model based on the "methylotype" has recently been proposed for MDS in an effort to predict overall and progression-free survival probabilities, adding a useful prognostic tool [35].

In the present study we report the identification of $S N K / P L K 2$ as a novel hypermethylated gene in a high percentage of patients with myeloid malignancies. 
The frequency of methylation was higher in MDS (88.4\%) than in AML (68.9\%). We also observed that aberrant methylation was detected in $26(68.4 \%)$ low and intermediate risk MDS patients in comparison to the 12 (31.6\%) higher risk groups of patients $(\mathrm{p}=0.04)$ (same results were obtained when the IPSS was used instead of the WPSS). This finding is a potential explanation, at least in part, for the increased apoptosis that characterizes early stage MDS. Although we did not demonstrate transcriptional silencing of the gene, it is well known that $\mathrm{CpG}$ islands methylation is associated with aberrant transcription silencing and inactivation of tumour suppressor genes [36], and as drug induced silencing of the SNK/PLK2 gene results in accentuated apoptosis [13], aberrant cytosine methylation of the specific gene can be a potential mechanism of increased apoptosis in early MDS. Methylation-dependent transcriptional silencing of $S N K / P L K 2$ has previously been demonstrated in Burkitt (and other) B-cell lymphomas [18]. The present data further extend the involvement of down-regulation of this gene in hematological neoplasia. An interesting finding was also a tendency for improved survival for both AML and MDS patients who displayed hypermethylation of the $S N K / P L K 2$ gene, suggesting that $S N K / P L K 2$ may have utility as a prognostic biomarker in myeloid malignancies.

MTHFR activity plays an important role in DNA synthesis and methylation reactions, and its reduced activity has been as sociated with abnormal DNA synthesis and repair, chromosomal instability, and alterations of the key pathway of the methylation resulting in an increased cancer risk [37]. We were therefore interested to establish the distribution of the two most common polymorphisms, MTHFR A1298C and MTHFR C677T, in the AML group of patients and to determine whether correlations exist between methylation in the SNK/PLK2 CpG island and specific MTHFR genotypes. The frequencies of the C677C, C677T, and T677T polymorphisms were 20\%, 68.9\%, 
and $11.1 \%$ in the AML cases, while A1298A, A1298C, and C1298C were present in $60 \%, 31 \%$, and $8.9 \%$ of cases respectively. There were no significant differences in allele frequencies between cases and controls (we studied 70 samples of healthy blood donors-data not shown), arguing against association between different genotypes and the susceptibility to develop AML. Our data are consistent with those of other studies who evaluated the two MTHFR polymorphisms in adult AML patients [38-40]. Patients with the C677T genotype had a better OS with a relative risk of death reduced by $66 \%(\mathrm{HR}=0.34, \mathrm{p}=0.017)$, while the $M T H F R$ A1298C polymorphism had no impact on OS. However, the CC genotypes (for both polymorphisms) were positively associated with $S N K / P L K 2$ methylation (Table 4). SNK/PLK2 methylation was associated with a trend for better OS when considered together to A1298A genotype $(\mathrm{HR}=1.80, \mathrm{p}=0.37)$, and with a better $\mathrm{OS}(\mathrm{HR}=0.3, \mathrm{p}=0.05)$ and a $64 \%$ relative reduction in the risk of death when considered with the C677T genotype, in comparison to all other polymorphisms. Our results indicate that although MTHFR polymorphisms do not play a direct role in the risk of AML development, they may be indirectly implicated in the pathogenesis of the disease as they do correlate with the aberrant methylation of the SNK/PLK2 CpG islands, and that their association could pred ict prognosis.

The tyrosine kinase receptor FLT3 controls normal hematopoiesis through regulation of transcription, proliferation, metabolism and apoptosis, and is one of the most commonly mutated genes in AML. The FLT3-ITD type of mutation is seen in $15-35 \%$ of AML patients and is associated with an overall poor prognosis disease [41]. FLT3-ITD was detected in $15.6 \%$ of AML cases consistent with published literature. FLT3-ITD positive patients had shorter OS in comparison with the FLT3ITD negative individuals, a difference that was not significant. We also found that 
AML patients harbouring both the FLT3 mutation and SNK/PLK2 methylation had a trend for worse survival in relation to those patients who were FLT3 wild-type and SNK/PLK2 methylated. FLT3-ITD positive patients are characterized by cytokineindependent cellular proliferation, and one can argue that reduced survival is expected in these subjects, but given the statistic results, we can hypothesize that $S N K / P L K 2$ methylation, and consequent gene silencing might affect the apoptosis/proliferation ratio.

In conclusion, we have identified $S N K / P L K 2$ as a novel epigenetically regulated gene in AML and MDS and we show that methylation occurs at high frequency in both diseases. We have studied possible interactions between $S N K / P L K 2$ methylation and the molecular marker FLT3 (an established genetic change in AML) and with germline MTHFR polymorphisms which are important for appropriate DNA methylation. We have also tested the possibility that analysis of these molecular genetic variables might impact on clinical outcome. Drug-induced SNK/PLK2 silencing has been determined to lead in increased cell apoptosis rate [13], which is also a characteristic of early stage MDS. Thus, we assume that reactivation of SNK/PLK2 expression with hypomethylating agents used for the treatment of MDS could be of help, probably by decreasing the pronounced apoptosis rate observed in this subset of MDS. Moreover, given that SNK/PLK2 methylation has been demonstrated to be involved in the pathogenesis of B-cell lymphomas [18], we hypothesize that it might also be associated with the pathogenesis of myeloid malignancies. It will clearly be of interest to extend our finding to a larger patient population to verify these initial observations. 


\section{References}

1. Esteller M. Epigenetics in cancer. N Engl J Med 2008;358:1148-1159.

2. Rush LJ, Plass C. Alterations of DNA methylation in hematologic malignancies. Cancer Lett 2002;185:1-12.

3. Baylin SB. DNA methylation and gene silencing in cancer. Nat Clin Pract Oncol2005;2 Suppl 1:S4-11.

4. Robertson KD. DNA methylation and human disease. Nat Rev Genet 2005;6:597-610.

5. Rice KL, Hormaeche I, Licht JD. Epigenetic regulation of normal and malignant hematopoiesis. Oncogene 2007;26:6697-6714.

6. Boultwood J, Wainscoat JS. Gene silencing by DNA methylation in haematological malignancies. Br J Haematol 2007;138:3-11.

7. Donaldson MM, Tavares AA, Hagan IM, Nigg EA, Glover DM. The mitotic roles of Polo- like kinase. J Cell Sci 2001;114:2357-2358.

8. Smith P, Syed N, Crook T. Epigenetic inactivation implies a tumor suppressor function in hematologic malignancies for Polo-like kinase 2 but not Polo-like kinase 3. Cell Cycle 2006;5:1262-1264. 
9. van de Weerdt BC, Medema RH.Polo-like kinases: a team in control of the division. Cell Cycle 2006;5:853-864.

10. Cizmecioglu O, Warnke S, Arnold M, Duensing S, Hoffmann I. Plk2 regulated centriole duplication is dependent on its localization to the centrioles and a functional polo-box domain. Cell Cycle 2008;7:3548-3555.

11. Winkles JA, Alberts GF. Differential regulation of polo-like kinase 1, 2, 3, and 4 gene expression in mammalian cells and tissues. Oncogene 2005;24:260266.

12. Ma S, Charron J, Erikson RL. Role of Plk2 (Snk) in mouse development and cell proliferation. Mol Cell Biol 2003;23:6936-6943.

13. Burns TF, Fei P, Scata KA, Dicker DT, El-Deiry WS. Silencing of the novel p53 target gene Snk/Plk2 leads to mitotic catastrophe in paclitaxel (taxol)exposed cells. Mol Cell Biol 2003;23:5556-5571.

14. Eckerdt F, Yuan J, Strebhardt K. Polo- like kinases and oncogenesis. Oncogene $2005 ; 24: 267-276$.

15. Krämer A, Neben K, Ho AD. Centrosome aberrations in hematological malignancies. Cell Biol Int 2005;29:375-383. 
16. Matthew EM, Hart LS, Astrinid is A, Navaraj A, Dolloff NG, Dicker DT, Henske EP, El-Deiry WS. The p53 target Plk2 interacts with TSC proteins impacting mTOR signaling, tumor growth and chemosensitivity under hypoxic conditions. Cell Cycle 2009;8:4168-4175.

17. Hatzimichael E, Dasoula A, Benetatos L, Syed N, Dranitsaris G, Crook T, Bourantas K.Study of specific genetic and epigenetic variables in multiple myeloma. Leuk Lymphoma. 2010;51:2270-2274.

18. Syed N, Smith P, Sullivan A, Spender LC, Dyer M, Karran L, O'Nions J, Allday M, Hoffmann I, Crawford D, Griffin B, Farrell PJ, Crook T. Transcriptional silencing of Polo-like kinase 2 (SNK/PLK2) is a frequent event in B-cell malignancies. Blood 2006;107:250-256.

19. Vardiman JW, Thiele J, Arber DA, Brunning RD, Borowitz MJ, Porwit A, Harris NL, Le Beau MM, Hellström-Lindberg E, Tefferi A, Bloomfield CD. The 2008 revision of the World Health Organization (WHO) classification of myeloid neoplasms and acute leukemia: rationale and important changes. Blood 2009;114:937-951.

20. Valent P, Horny HP, Bennett JM, Fonatsch C, Germing U, Greenberg P, Haferlach T, Haase D, Kolb HJ, Krieger O, Loken M, van de Loosdrecht A, Ogata K, Orfao A, Pfeilstöcker M, Rüter B, Sperr WR, Stauder R, Wells DA. Definitions and standards in the diagnosis and treatment of the 
myelodysplastic syndromes: Consensus statements and report from a working conference. Leuk Res 2007;31:727-736.

21. Malcovati L, Germing U, Kuendgen A, Della Porta MG, Pascutto C, Invernizzi R, Giagounidis A, Hildebrandt B, Bernasconi P, Knipp S, Strupp C, Lazzarino M, Aul C, Cazzola M. Time-dependent prognostic scoring system for predicting survival and leukemic evolution in myelodysplastic syndromes. J Clin Oncol 2007;25:3503-3510.

22. Fröhling S, Scholl C, Gilliland DG, Levine RL. Genetics of myeloid malignancies: pathogenetic and clinical implications. J Clin Oncol $2005 ; 23: 6285-6295$.

23. Skibola CF, Smith MT, Kane E, Roman E, Rollinson S, Cartwright RA, Morgan G. Polymorphisms in the methylenetetrahydrofolatereductase gene are associated with susceptibility to acute leukemia in adults. Proc Natl Acad Sci U S A 1999;96:12810-12815.

24. Cheson BD, Bennett JM, Kopecky KJ, Büchner T, Willman CL, Estey EH, Schiffer CA, Doehner H, Tallman MS, Lister TA, Lo-Coco F, Willemze R, Biondi A, Hiddemann W, Larson RA, Löwenberg B, Sanz MA, Head DR, Ohno R, Bloomfield CD; International Working Group for Diagnosis, Standardization of Response Criteria, Treatment Outcomes, and Reporting Standards for Therapeutic Trials in Acute Myeloid Leukemia. Revised recommendations of the International Working Group for Diagnosis, 
Standardization of Response Criteria, Treatment Outcomes, and Reporting Standards for Therapeutic Trials in Acute Myeloid Leukemia. J Clin Oncol 2003;21:4642-4649.

25. Nimer SD. Myelodysplastic syndromes. Blood 2008;111:4841-4851.

26. Tefferi A, Vardiman JW. Myelodysplastic syndromes. N Engl J Med 2009;361:1872-1885.

27. Renneville A, Roumier C, Biggio V, Nibourel O, Boissel N, Fenaux P, Preudhomme C. Cooperating gene mutations in acute myeloid leukemia: a review of the literature. Leukemia $2008 ; 22: 915-931$.

28. Esteller M. Profiling aberrant DNA methylation in hematologic neoplasms: a view from the tip of the iceberg. Clin Immunol 2003;109:80-88.

29. Figueroa ME, Lugthart S, Li Y, Erpelinck-Verschueren C, Deng X, Christos PJ, Schifano E, Booth J, van Putten W, Skrabanek L, Campagne F, Mazumdar M, Greally JM, Valk PJ, Löwenberg B, Delwel R, Melnick A. DNA methylation signatures identify biologically distinct subtypes in acute myeloid leukemia. Cancer Cell 2010;17:13-27.

30. Kroeger H, Jelinek J, Estécio MR, He R, Kondo K, Chung W, Zhang L, Shen L, Kantarjian HM, Bueso-Ramos CE, Issa JP. Aberrant CpG island 
methylation in acute myeloid leukemia is accentuated at relapse. Blood 2008;112:1366-1373.

31. Deneberg S, Grövdal M, Karimi M, Jansson M, Nahi H, Corbacioglu A, Gaidzik V, Döhner K, Paul C, Ekström TJ, Hellström-Lindberg E, Lehmann S. Gene-specific and global methylation patterns predict outcome in patients with acute myeloid leukemia. Leukemia 2010;24:932-941.

32. Jiang Y, Dunbar A, Gondek LP, Mohan S, Rataul M, O'Keefe C, Sekeres M, Saunthararajah Y, Maciejewski JP. Aberrant DNA methylation is a dominant mechanism in MDS progression to AML. Blood 2009;113:1315-1325.

33. Wu SJ, Yao M, Chou WC, Tang JL, Chen CY, Ko BS, Huang SY, Tsay W, Chen YC, Shen MC, Wang CH, Yeh YC, Tien HF. Clinical implications of SOCS1 methylation in myelodysplastic syndrome. $\mathrm{Br} \mathrm{J}$ Haematol 2006;135:317-323.

34. Potapova A, Hasemeier B, Römermann D, Metzig K, Göhring G, Schlegelberger B, Länger F, Kreipe H, Lehmann U. Epigenetic inactivation of tumour suppressor gene KLF11 in myelodysplastic syndromes. Eur J Haematol 2010;84:298-303.

35. Shen L, Kantarjian H, Guo Y, Lin E, Shan J, Huang X, Berry D, Ahmed S, Zhu W, Pierce S, Kondo Y, Oki Y, Jelinek J, Saba H, Estey E, Issa JP. DNA 
methylation predicts survival and response to therapy in patients with myelodysplastic syndromes. J Clin Oncol 2010;28:605-613.

36. Herman JG, Baylin SB. Gene silencing in cancer in association with promoter hypermethylation. N Engl J Med 2003;349:2042-2054.

37. Dong LM, Potter JD, White E, Ulrich CM, Cardon LR, Peters U. Genetic susceptibility to cancer: the role of polymorphisms in candidate genes. JAMA 2008;299:2423-2436.

38. Kim HN, Kim YK, Lee IK, Yang DH, Lee JJ, Shin MH, Park KS, Choi JS, Park MR, Jo DY, Won JH, Kwak JY, Kim HJ. Association between polymorphisms of folate-metabolizing enzymes and hematological malignancies. Leuk Res 2009;33:82-87.

39. Guillem VM, Collado M, Terol MJ, Calasanz MJ, Esteve J, Gonzalez M, Sanzo C, Nomdedeu J, Bolufer P, Lluch A, Tormo M. Role of MTHFR (677, 1298) haplotype in the risk of developing secondary leukemia after treatment of breast cancer and hematological malignancies. Leukemia 2007;21:14131422.

40. Bolufer P, Collado M, Barragan E, Calasanz MJ, Colomer D, Tormo M, González M, Brunet S, Batlle M, Cervera J, Sanz MA.Profile of polymorphisms of drug-metabolising enzymes and the risk of therapy-related leukaemia. Br J Haematol 2007;136:590-596. 
41. Meshinchi S, Appelbaum FR. Structural and functional alterations of FLT3 in acute myeloid leukemia. Clin Cancer Res 2009;15:4263-4269. 
Figure 1. Methylation specific PCR on SNK/PLK2 methylation. Sample blk (blank) indicates a sample containing no DNA. Sample cmeth (methylated control) is a commercially available universally methylated sample. Samples 1 and 2 belong to patients with abnormal methylation of the SNK/PLK2 gene. Both bands for the umethylated and methlylated allele are generated. Sample 3 belong to a subject with normal methylation profile. m: methylated, u: unmethylated, L: ladder 


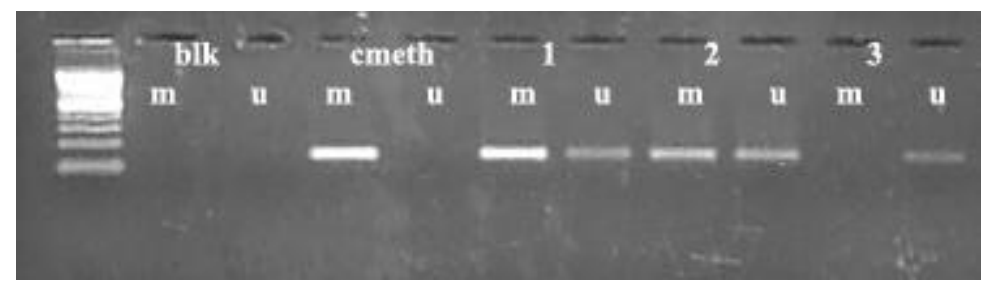




\begin{tabular}{|c|c|}
\hline \multicolumn{2}{|l|}{ Patients' Characte ristics } \\
\hline \multicolumn{2}{|l|}{ Gender } \\
\hline Male & $58(65.9 \%)$ \\
\hline Female & $30(34.1 \%)$ \\
\hline Age (range) & $71.5 \pm 13.2(16-92)$ \\
\hline \multicolumn{2}{|l|}{ Blood cell count } \\
\hline Hb gr/dl (mean-range) & $9 \pm 1.7(3.4-13.2)$ \\
\hline WBC $\times 10^{9} / 1$ (mean-range) & $18.9 \pm 36.2(0.2-200)$ \\
\hline Plt x10/1 (mean-range) & $105.9 \pm 120.5(1-650)$ \\
\hline \multicolumn{2}{|l|}{ Cytogenetics } \\
\hline Favorable & $35(46 \%)$ \\
\hline Intermediate & $23(30.3 \%)$ \\
\hline Adverse & $18(23.7 \%)$ \\
\hline Acute Myeloid Leukemia & $45(51.1 \%)$ \\
\hline $\mathrm{t}(8 ; 21)$ & $1(1.1 \%)$ \\
\hline $\mathrm{t}(15 ; 17)$ & $1(1.1 \%)$ \\
\hline with myelodysplasia related changes & $16(18.2 \%)$ \\
\hline therapy-related myeloid neoplasms & $1(1.1 \%)$ \\
\hline with minimal differentiation & $5(5.7 \%)$ \\
\hline without maturation & $9(10.2 \%)$ \\
\hline with maturation & $5(5.7 \%)$ \\
\hline acute myelomonocytic leukemia & $3(3.4 \%)$ \\
\hline acute monoblastic/monocytic leukemia & $4(4.6 \%)$ \\
\hline \multicolumn{2}{|l|}{ FLT3-ITD } \\
\hline Positive & $7(15.6 \%)$ \\
\hline Negative & $38(84.4 \%)$ \\
\hline \multicolumn{2}{|l|}{ MTHFR A1298C } \\
\hline $\mathrm{AA}$ & $27(60 \%)$ \\
\hline $\mathrm{AC}$ & $14(31.1 \%)$ \\
\hline $\mathrm{CC}$ & $4(8.9 \%)$ \\
\hline MTHFR C677T & \\
\hline
\end{tabular}


Myelodysplastic syndromes

$43(48.9 \%)$

RA

$8(9.1 \%)$

$\mathrm{RN}$

$2(2.3 \%)$

RT

$1(1.1 \%)$

RCMD

17 (19.3\%)

RAEB-I

7 (8\%)

RAEB-II

$6(6.8 \%)$

$\operatorname{del} 5 \mathrm{q}$

$2(2.3 \%)$

\section{WPSS}

Very low

$7(16.3 \%)$

Low

$13(30.2 \%)$

Intermediate

$10(23.3 \%)$

High

$10(23.3 \%)$

Very high

$3(7 \%)$

Table 1: Patients' characteristics partecipanting in the study

$\mathrm{Hb}$ : hemoglobin, WBC: white blood cell count, Plt: platelet count, FLT3-ITD: FLT3iternal tandem duplication, MTHFR: methylenetetrahydrofolate reductase, RA: refractory anemia, $\mathrm{RN}$ : refractory neutropenia, RT: refractory thrombocytopenia, RCMD: refractory cytopenias with multilineage dysplasia, RAEB: refractory anemia with excess blasts, WPSS: WHO based classification prognostic scoring system 


\begin{tabular}{|c|c|c|}
\hline Gene & Prime rs & $\begin{array}{l}\mathbf{T}_{\text {ann }} / \\
\text { Cycles }\end{array}$ \\
\hline SNK/PLK2 & $\begin{array}{l}\text { MF: 5'-GAT-A-GG-GTT-CGT-TTG-TAG-TTG-TTT-C-3', } \\
\text { MR: 5'-TAA-AAT-CCT-AAC-ACG-ATT-AAC-CGA-T-3' } \\
\text { UF: 5'-TAG-GGT-TTG-TTT-GTA-GTT-GTT-TTG-T-3' } \\
\text { UR: 5'-AAT-AAA-ATC-CTA-ACA-CAA-TTA-ACC-AAT-3' }\end{array}$ & $56^{\circ} \mathrm{C} / 40$ \\
\hline MTHFR A1298C & $\begin{array}{l}\text { F: 5'-CTT-TGG-GGA-GCT-GAA-GGA-CTA-CTA-3' } \\
\text { R: 5'-CAC-TTT-GTG-ACC-ATT-CCG-GTT-TG-3' }\end{array}$ & $62^{\circ} \mathrm{C} / 30$ \\
\hline MTHFR C677T & $\begin{array}{l}\text { F: 5'-TGA-AGG-AGA-AGG-TGT-CTG-CGG-GA-3' } \\
\text { R: 5'-AGG-ACG-GTG-CGG-TGA-GAG-TG-3' }\end{array}$ & $60^{\circ} \mathrm{C} / 38$ \\
\hline FLT3-ITD & $\begin{array}{l}\text { 11F:5'- GCA-ATT-TAG-GTA-TGA-AAG-CCA-GC-3' } \\
\text { 12R: 5'-CTT-TCA-GCA-TTT-TGA-CGG-CAA-CC-3' }\end{array}$ & $62^{\circ} \mathrm{C} / 30$ \\
\hline
\end{tabular}

Table 2: Primers used in experimental procedures

$\mathrm{T}_{\mathrm{ann}}$ : annealing temperature, MF: Methylated forward, MR: methylated reverse, UF:

unmethylated forward, UR: unmethylated reverse 
Patients No 88

MDS

Cytogenetics
SNK/PLK2 methylation 69/88 (78.4\%)

$38 / 43(88.4 \%)$ 
Favorable

Intermediate

Poor

WHO subtype

RA

$\mathrm{RN}$

RT

RCMD

RAEB-I

RAEB-II

$\operatorname{del} 5 q$

WPSS

Very low

Low

Intermediate

High

Very high
29/33 (87.9\%)

$3 / 3(100 \%)$

6/7 (85.7\%)

$6 / 8(75 \%)$

$2 / 2(100 \%)$

1/1 (100\%)

16/17 (94.1\%)

$5 / 7(71.4 \%)$

6/6 (100\%)

$2 / 2(100 \%)$

$6 / 7(85.7 \%)$

$12 / 13(92.3 \%)$

$8 / 10(80 \%)$

9/10 (90\%)

$3 / 3(100 \%)$

Table 3: Clinical findings of MDS patients with SNK/PLK2 methylation.

RA: refractory anemia, RN: refractory neutropenia, RT: refractory thrombocytopenia, RCMD: refractory cytopenias with multilineage dysplasias, RAEB: refractory anemia with excess blasts, WPSS: WHO classification based prognostic scoring system 


\section{Patients No 88}

$\overline{A M L}$

Cytogenetics

Favorable

Intermediate

Poor

WHO subtype

$\mathrm{t}(8 ; 21)$

$\mathrm{t}(15 ; 17)$

with myelodysplasia related changes

therapy-related myeloid neoplasms

with minimal differentiation

without maturation

with maturation

acute myelomonocytic leukemia

acute monoblastic/monocytic leukemia

MTHFR A1298C

AA

$\mathrm{AC}$

CC

MTHFR C677T

$\mathrm{CC}$

CT
SNK/PLK2 methylation 69/88 (78.4\%)

$31 / 45(68.9 \%)$

$2 / 2(100 \%)$

$15 / 20(75 \%)$

$4 / 11(36.4 \%)$

$1 / 1(100 \%)$

$1 / 1(100 \%)$

$10 / 16(62.5 \%)$

$1 / 1(100 \%)$

$4 / 5(80 \%)$

$6 / 9(66.7 \%)$

$3 / 5(60 \%)$

$3 / 3(100 \%)$

$2 / 4(50 \%)$

19/27 (70.4\%)

$9 / 14(64.3 \%)$

$3 / 4(75 \%)$

$7 / 9(77.8 \%)$

$22 / 31(71 \%)$ 
FLT3-ITD positive $4 / 7(57.1 \%)$

Table 4: Clinical findings of acute myeloid leukemia (AML) patients with $\underline{\text { SNK/PLK2 methylation }}$

FLT3-ITD: FLT3-iternal tandem duplication, MTHFR: methylenetetrahydrofolate reductase 
$\underline{\mathbf{A}}$

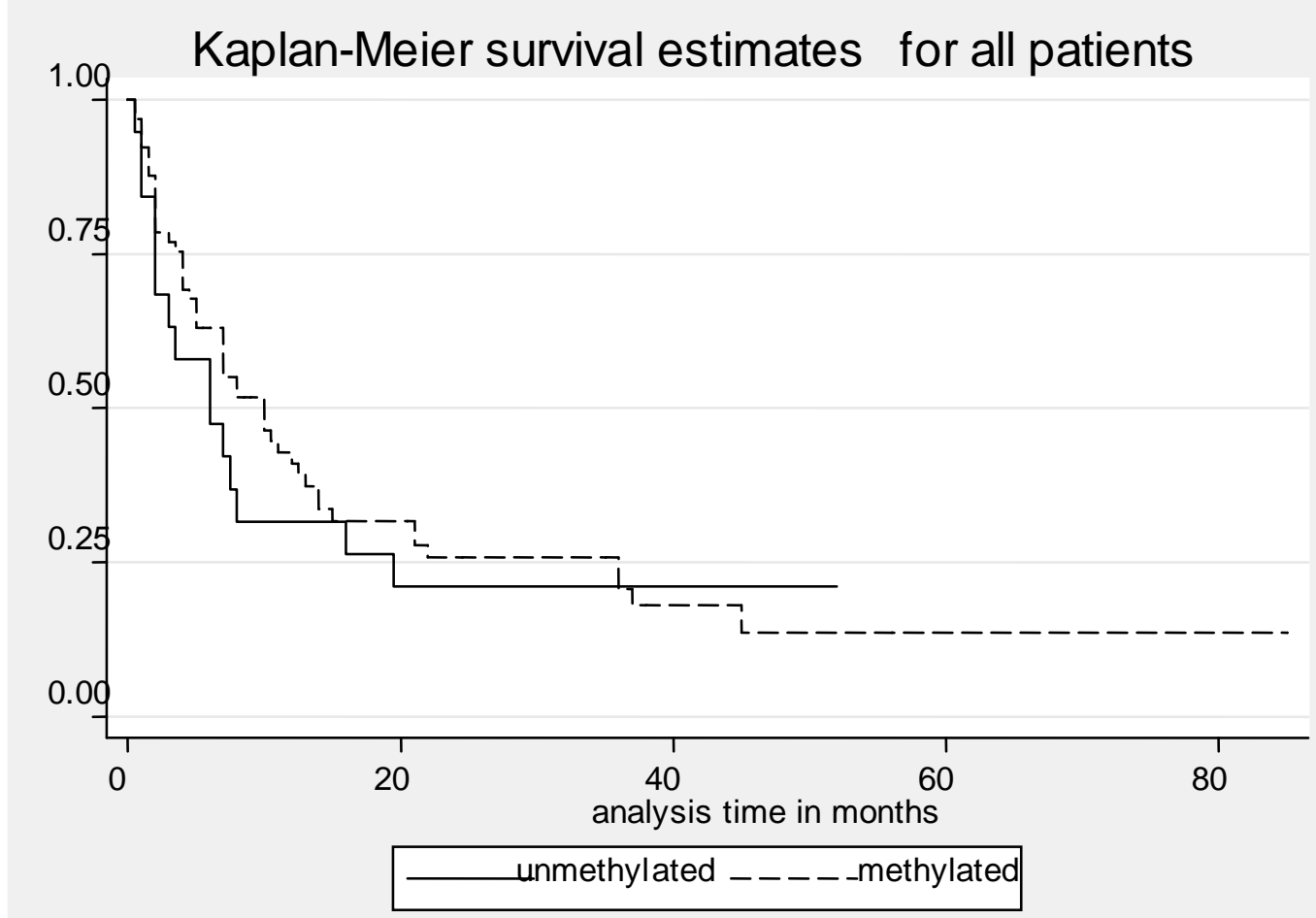

B

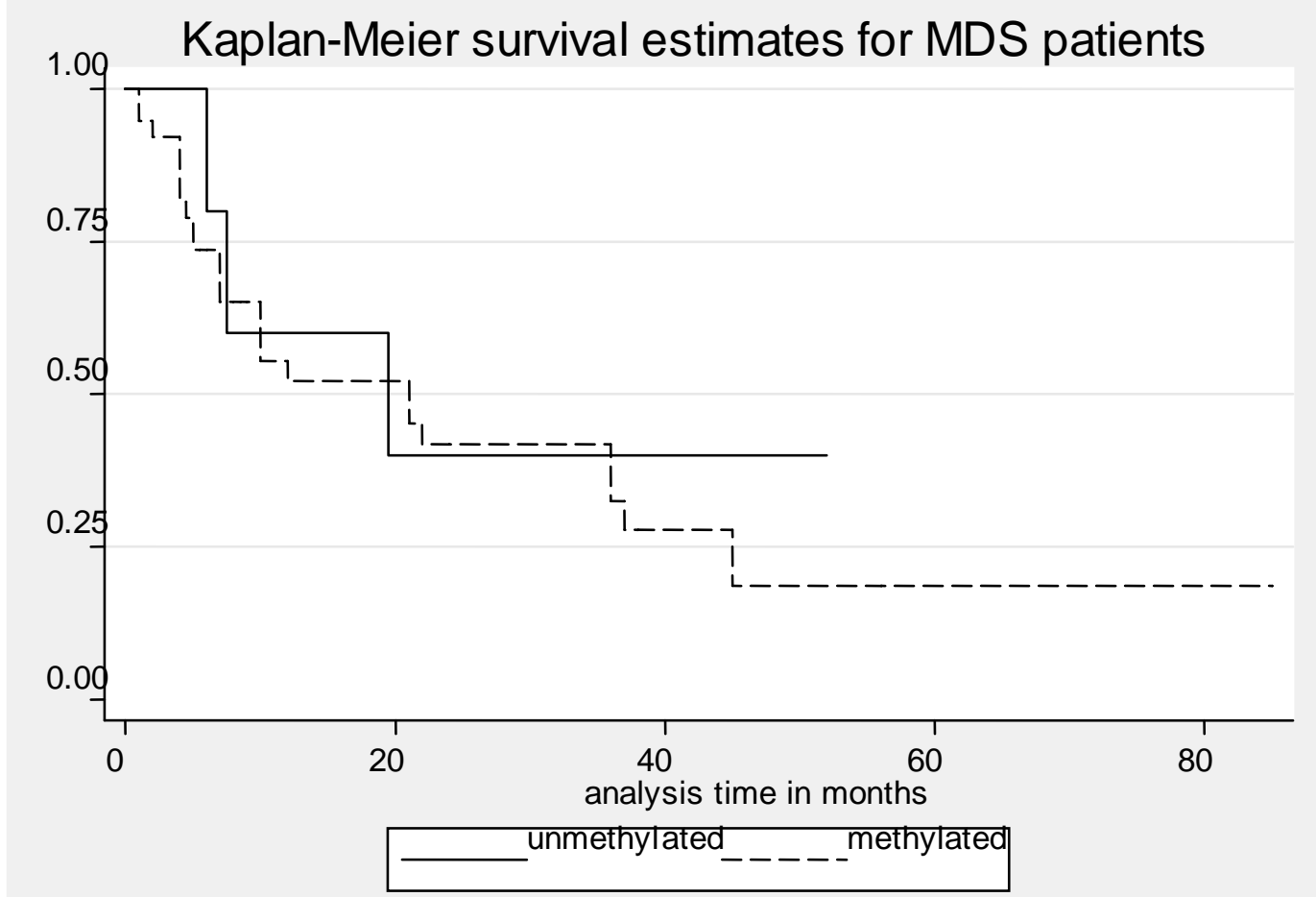

$\underline{\mathbf{C}}$ 


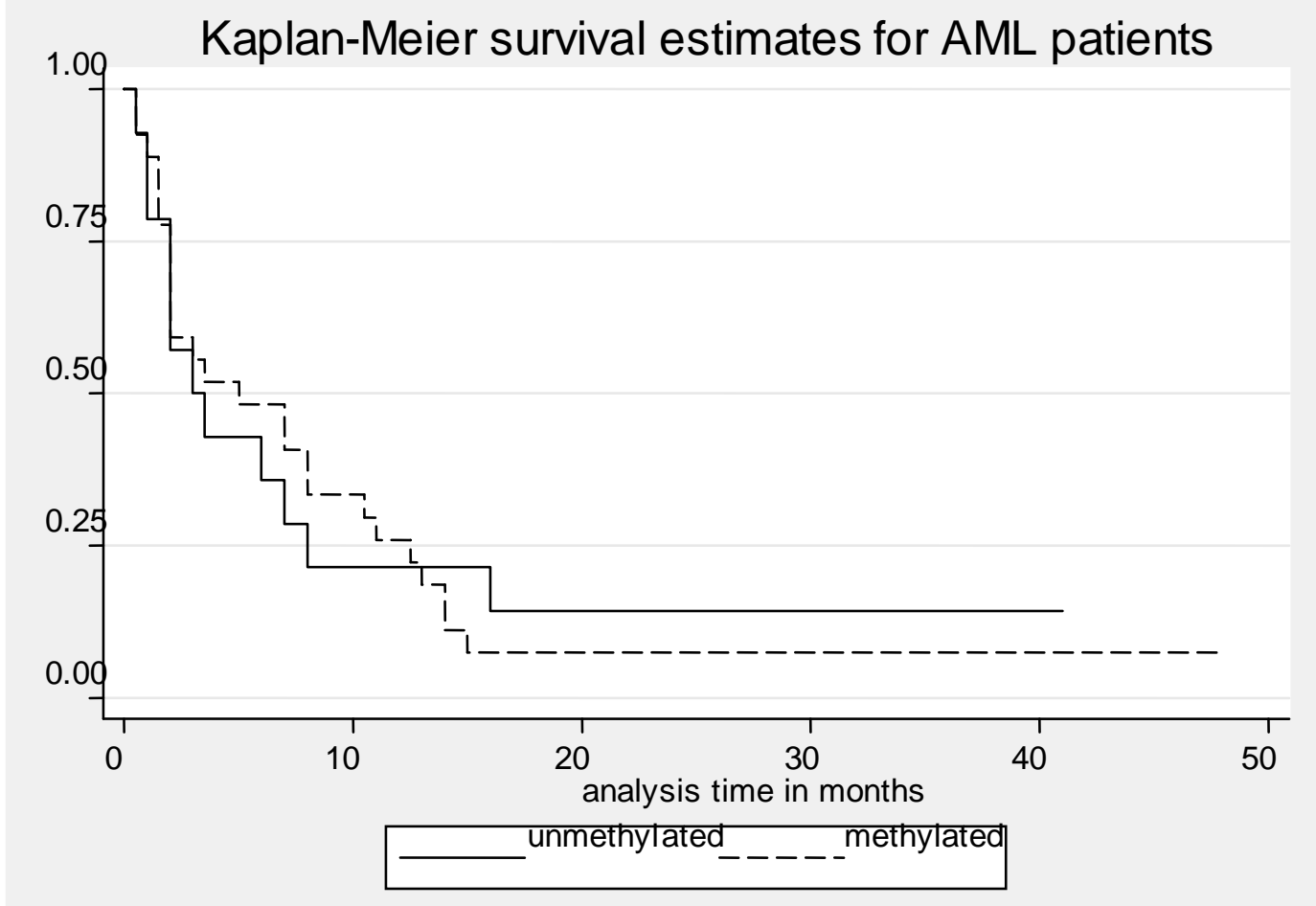

Table 5: Kaplan-Meier survival estimates in respect of the SNK/PLK2 methylation $\underline{\text { status }}$

A: all patients, B: Myelodysplastic syndrome (MDS) patients, C: Acute myeloid leukemia (AML) patients 
Kaplan-Meier survival estimates by MTHFR A1298C polymorphisms

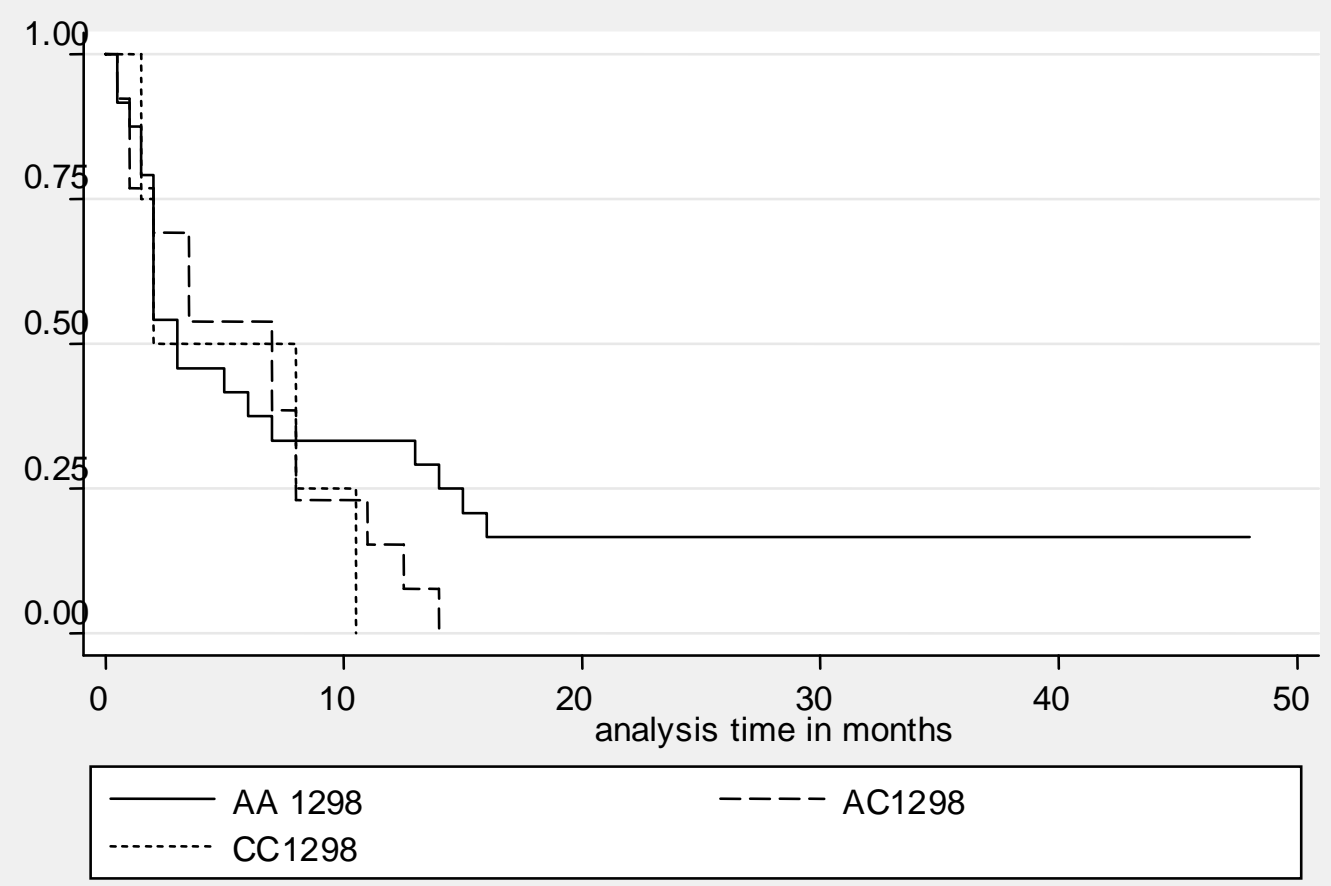

$\underline{\mathbf{B}}$

Kaplan-Meier survival estimates by MTHFR A1298C and SNK/PLK2 methylation

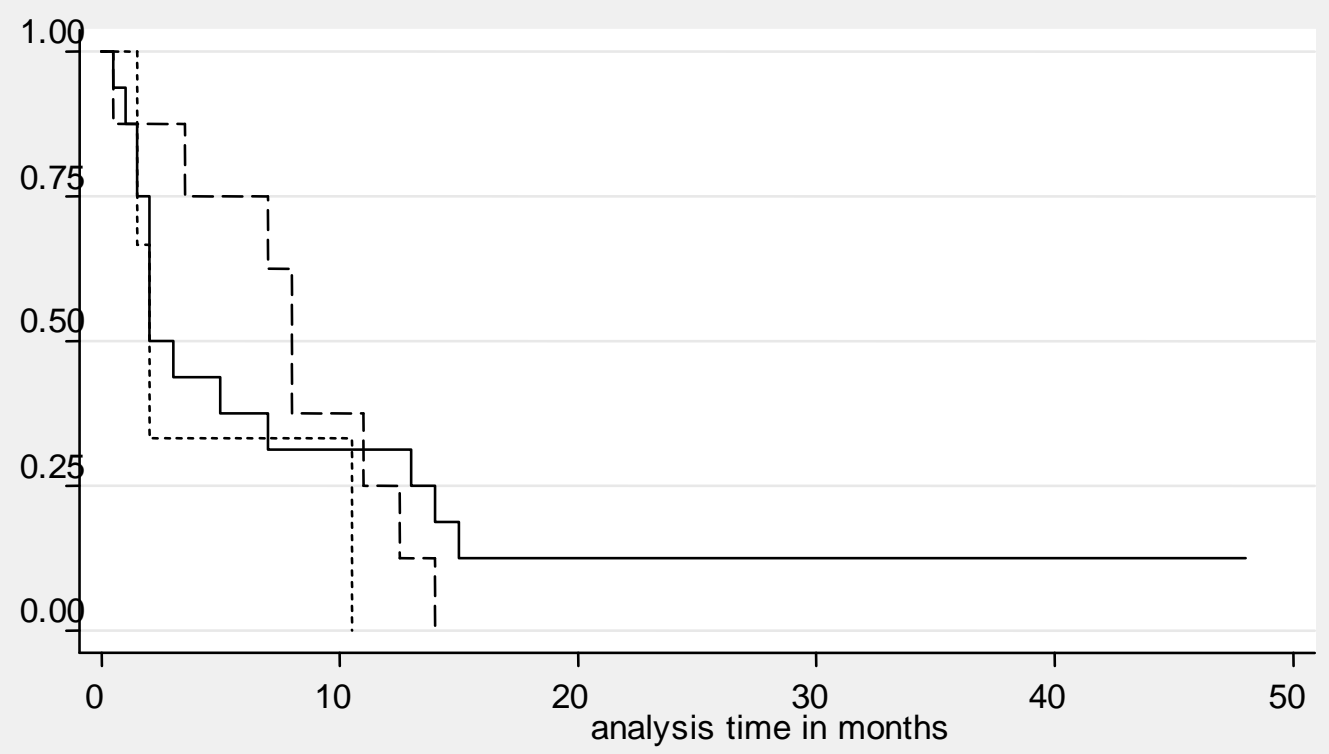

- AA1298/ SNK/PLK2 methylated---- AC1298/ SNK/PLK2 methylated CC1298/ SNK/PLK2 methylated 
Kaplan-Meier survival estimates by MTHFR C677T polymorphisms

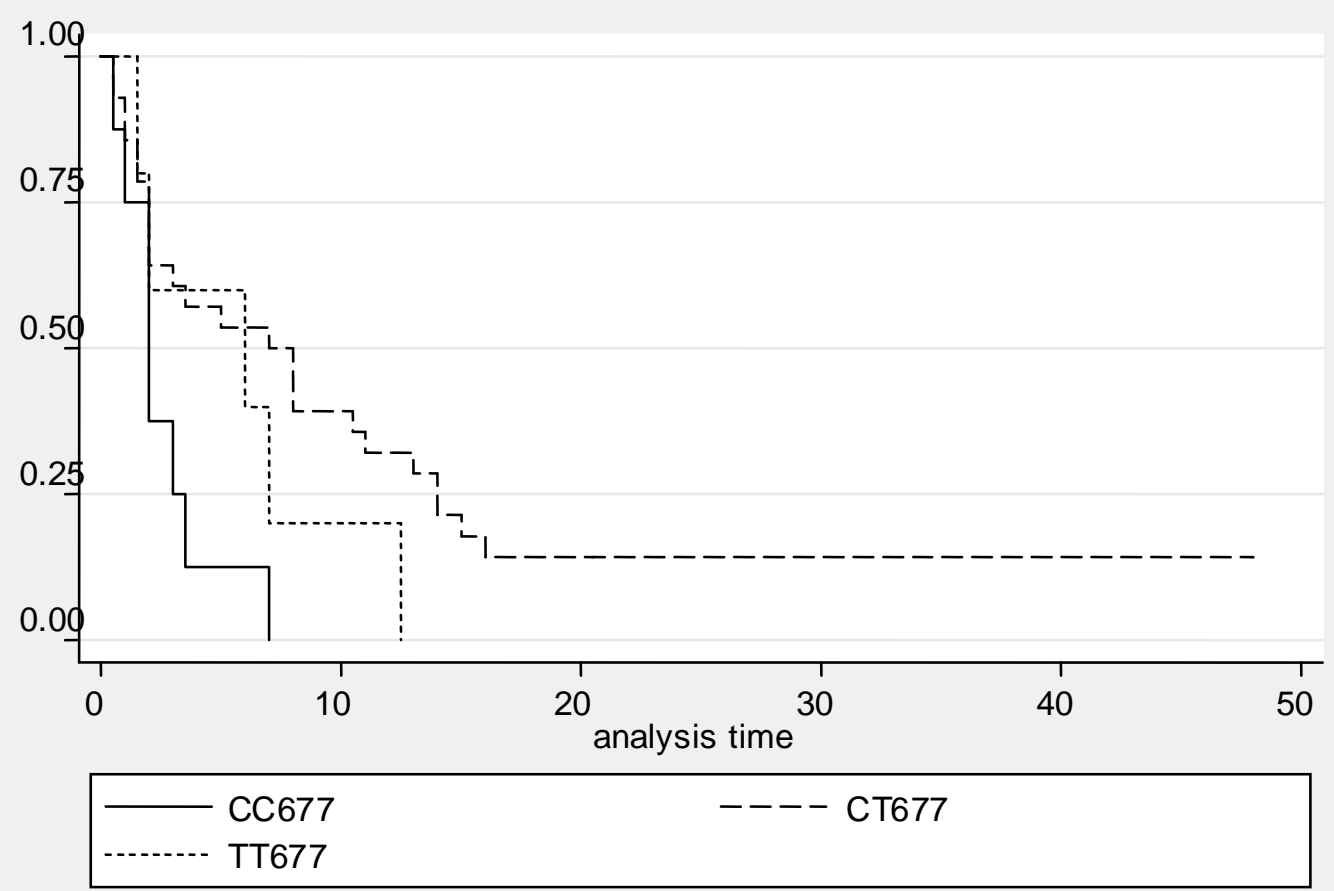

$\underline{\mathbf{D}}$

Kaplan-Meier survival estimates by MTHFR C677T and SNK/PLK2 methylation

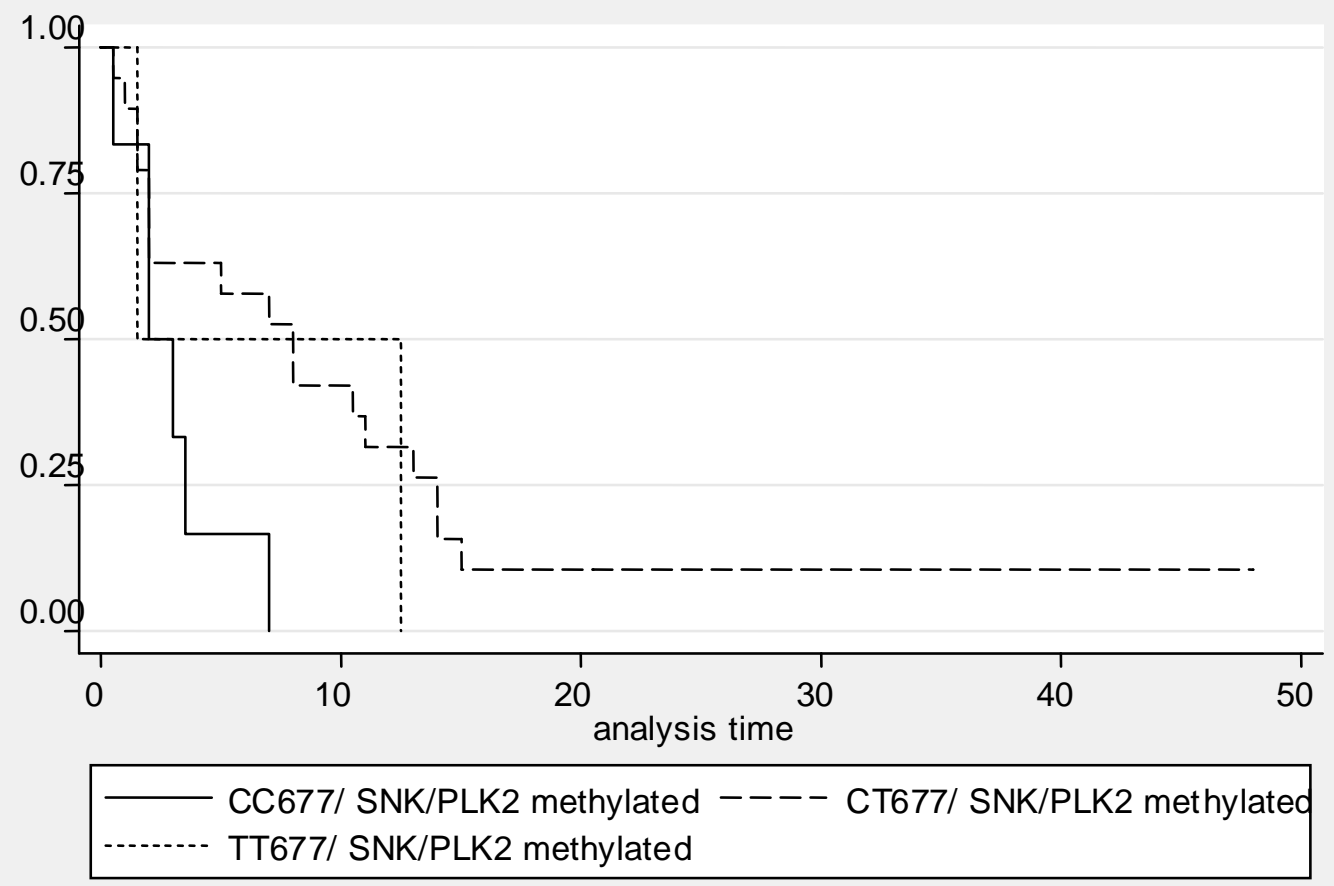

Table 6: Kaplan-Meier survival estimates presentinh MTHFR polymorphisms in acute myeloid leukemia patients 
A: survival estimates by AA1298, AC1298, and CC1298 polymorphisms. Cox regression analysis was relative to the AA polymorphism. B: survival estimates in respect to patients' A1298C genotypes and combined with SNK/PLK2 methylation, C: survival estimates by CC677, CT677, and TT677 polymorphisms. Cox regression analysis was relative to the CC polymorphism, D: survival estimates in respect to patients' C677T genotypes and combined with SNK/PLK2 methylation 